\title{
Risk Factors for Contrast-Induced Nephropathy
}

\author{
Omer Toprak ${ }^{\mathrm{a}, \mathrm{b}}$ Mustafa Cirit ${ }^{\mathrm{a}}$ \\ ${ }^{a}$ Department of Nephrology, Atatürk Training and Research Hospital, Izmir, Turkey; ${ }^{b}$ Division of Nephrology, \\ Department of Medicine, Vanderbilt University School of Medicine, Nashville, Tenn., USA
}

\section{Key Words}

Contrast media, nephropathy $\cdot$ Contrast-induced nephropathy $\cdot$ Coronary angiography, contrast-induced nephropathy $\cdot$ Risk factors, contrast-induced nephropathy

\begin{abstract}
An increasing number of diagnostic imaging and interventional procedures require the use of radiographic contrast agents which has led to a parallel increase in the incidence of contrast-induced nephropathy (CIN). CIN is a serious clinical problem associated with increased morbidity and mortality, particularly in patients with chronic renal failure (see the Case Report). A key step to minimize CIN is to identify patients at risk of CIN. The aim of the present review was to summarize the knowledge about the risk factors of $\mathrm{CIN}$, including the review of ultimate clinical research and developments.

Copyright $\odot 2006$ S. Karger AG, Basel
\end{abstract}

\section{Case Report}

A 75-year-old female patient with a history of type 2 diabetes mellitus, congestive heart failure, hypertension, and chronic renal failure with an estimated glomerular filtration rate of $40 \mathrm{ml} / \mathrm{min}$ (baseline serum creatinine level $1.5 \mathrm{mg} / \mathrm{dl}$ ) was admitted to the hospital with acute myocardial infarction. She underwent emergency cardiac catheterization. Before coronary angiography, the patient received orally $600 \mathrm{mg} \mathrm{N}$-acetylcysteine and intravenously normal saline at $150 \mathrm{ml} / \mathrm{h}$. Two days later, the serum creatinine

\section{KARGER}

Fax +41613061234 E-Mail karger@karger.ch www.karger.com
(C) 2006 S. Karger AG, Basel

$1420-4096 / 06 / 0292-0084 \$ 23.50 / 0$

Accessible online at:

www.karger.com/kbr level increased to $4.8 \mathrm{mg} / \mathrm{dl}$, and the urine output decreased to $1,000 \mathrm{ml} /$ day. The patient's creatinine level increased to $5.6 \mathrm{mg} / \mathrm{dl}$ on the 5th day after cardiac catheterization. The diagnosis was contrast-induced nephropathy. After nephrology consultation, the patient underwent hemodialysis for two sessions. The creatinine level returned to baseline values over the next several days without need for hemodialysis. The hospital stay was approximately 8 days longer and the hospital care cost almost fourfold higher than in other patients.

\section{Introduction}

All contrast media (CM) used in vascular radiological procedures have an iodine-containing benzene ring. These procedures require intravascular administration of iodinated CM which is becoming a great source of an iatrogenic disease known as contrast-induced nephropathy (CIN) [1-5]. Iodinated CM can be very harmful to the kidneys, and this makes the prevention of CIN an important goal. The large number of patients who are severely affected by CIN underscores the importance of addressing known risk factors for CIN. The following review provides an overview of the current risk factors for CIN.

\section{Definition and Incidence of CIN}

The term CIN indicates an impairment of the renal function occurring within 3 days after intravascular administration of CM in the absence of an alternative etiol- 
ogy. According to the guidelines of the European Society of Urogenital Radiology, elevation of the serum creatinine level by $\geq 0.5 \mathrm{mg} / \mathrm{dl}$ or $\geq 25 \%$ within 3 days of CM injection is defined as CIN [6]. Typically, the serum creatinine level begins to increase $24-72 \mathrm{~h}$ after the administration of CM, peaks at 3-5 days, and usually returns to baseline values within 2 weeks. Serum creatinine is the standard marker to detect CIN. However, serum creatinine demonstrates major limitations. Serum cystatin $\mathrm{C}$ is a useful detection marker of acute renal failure and may indicate CIN 1-2 days earlier than creatinine [7]. Cystatin $\mathrm{C}$ has been found to reflect changes in glomerular filtration rate (GFR) more rapidly than does serum creatinine, and it has been proposed as an alternative endogenous marker of GFR, showing a higher correlation with standard clearance methods such as inulin or iohexol clearance [8]. The incidence of CIN is usually $<2 \%$ in patients who do not have any risk factor for CIN, but the incidence can be increased to $90 \%$ in patients at high risk of CIN $[3,9,10]$.

\section{Pathophysiology of CIN}

CIN is mediated predominantly by outer medullary hypoxic tubular damage, probably combined with and accentuated by endothelial dysfunction and renal microcirculatory alterations [11-14]. Altered protective mechanisms also bring about the susceptibility to develop CIN in high-risk patients. Indeed, predisposing risk factors, such as preexisting renal dysfunction, diabetes, and congestive heart failure, are all characterized by compromised medullary oxygen sufficiency, related to defective nitric-oxide-dependent renal vasodilatation or prostaglandin synthesis, by increased reabsorptive work load, by enhanced systemic vasoconstrictive stimuli, or by structural changes of the renal microcirculation [14]. Tubular obstruction, direct toxic effects of the dye because of apoptosis, and oxidative damage may also play a role [5].

\section{Clinical Course and Outcomes}

CIN is independently associated with increased inhospital and long-term mortality and increases the costs of medical care by at least extending the hospital stay. Approximately USD 180 million is spent annually to manage CIN in the USA [1]. CIN may range in severity from asymptomatic, nonoliguric transient renal dysfunction to oliguric severe renal failure that necessitates permanent dialysis or kidney transplantation. CIN is reported to be the third leading cause of acute renal failure $[1,2]$. Dangas et al. [15] showed that in-hospital outcome rates, such as of death (6.3 vs. $0.8 \%)$, cardiac death (4.0 vs. $0.5 \%)$, coronary artery bypass grafting ( 5.8 vs. $0.5 \%)$, major adverse cardiac events (9.3 vs. $1.1 \%$ ), packed red cell transfusions ( 28 vs. $6 \%$ ), vascular surgery of access site (5.6 vs. $2.6 \%)$, and postprocedure length of stay (6.8 \pm 7.1 vs. $2.3 \pm 2.5$ days), were significantly higher in patients who developed CIN as compared with control patients ( $\mathrm{p}<0.0001)$. In a cumulative 1 -year outcome analysis, hospital death, out-of-hospital death, and major adverse cardiac event rates were significantly higher in patients who developed CIN ( $<$ 0.0001) [15]. A study of patients with acute myocardial infarction who underwent primary angioplasty showed that those who developed CIN had a significantly higher incidence of highrate atrial fibrillation $(\mathrm{p}=0.01)$, high-degree conduction disturbances requiring a permanent pacemaker $(\mathrm{p}=$ $0.04)$, acute pulmonary edema $(\mathrm{p}=0.008)$, respiratory failure requiring mechanical ventilation $(\mathrm{p}<0.0001)$, cardiogenic shock requiring an intra-aortic balloon $(\mathrm{p}<$ 0.0001 ), and acute renal failure requiring renal replacement therapy $(\mathrm{p}<0.0001)[16]$. In a retrospective analysis of 16,248 patients who underwent CM examinations, the in-hospital mortality rates were almost fivefold higher [34 vs. 7\%; odds ratio $(\mathrm{OR})=6.5, \mathrm{p}<0.01]$ in CIN patients, and CIN was associated with sepsis, bleeding, coma, or respiratory failure [17]. In all the CIN studies, $0.3-4 \%$ of the patients required short-term hemodialysis. Renal failure requiring dialysis after coronary interventions is associated with a $36 \%$ in-hospital mortality rate and has a 2 -year mortality rate of $81 \%$ [1].

\section{Prevention Strategies}

The treatment of established CIN is limited to supportive measures and dialysis. For this reason, screening for high-risk patients before CM-including cardiac procedures and taking the appropriate prophylactic regimens are important in reducing CIN. Patients at risk of CIN can often be identified on the basis of routine medical history, physical examination, and laboratory analysis before the procedure. Identifying patients with renal insufficiency is the main goal. After the high-risk patient population has been identified and risk factors addressed, the next step in preventing CIN is the use of different prophylactic measures. Therapies that have been studied for the prevention 
of CIN include saline hydration, sodium bicarbonate, $\mathrm{N}$ acetylcysteine, theophylline, calcium channel blockers, diuretics, dopamine, endothelin antagonists, atrial natriuretic peptide, fenoldopam, captopril, prostaglandin $\mathrm{E}_{1}$, ascorbic acid, hemodialysis after CM administration, or hemofiltration during and after CM administration [1821]. Of all these measures, extracellular volume expansion with intravenous saline or sodium bicarbonate $(0.9 \%$ saline might be more beneficial than $0.45 \%$ saline), minimizing the dose of $\mathrm{CM}$, using low-osmolar nonionic $\mathrm{CM}$ instead of high-osmolar ionic CM, stopping the intake of nephrotoxic drugs, such as diuretics, nonsteroidal antiinflammatory drugs (NSAIDs), and cyclooxygenase-2 (COX-2) inhibitors, and avoiding short intervals between procedures requiring $\mathrm{CM}$ have all been shown to be effective in reducing CIN. Alternatives to ordinary CM, such as carbon dioxide or gadolinium chelates, can be used in patients at high risk of developing CIN. Gadolinium seems to be as nephrotoxic as iodine-based CM, even when used for angiographic magnetic resonance imaging procedures in patients with renal failure [22, 23]. More studies need to be done to better understand the effects of gadoliniumbased CM on CIN. Ultrasound contrast agents are microbubbles that produce acoustic enhancement, and they are pharmacologically almost inert and safe [24].

The protective role of acetylcysteine, which has been demonstrated by several recent clinical trials, may warrant its use in high-risk patients [19]. However, the administration of $\mathrm{N}$-acetylcysteine in at-risk patients might theoretically reduce the incidence of CIN, but this finding has not been uniform or always demonstrated by currently published trials $[20,25]$.

\section{Risk Factors for CIN}

Specific factors that increase the risk of developing $\mathrm{CIN}$ are related to the patient, the $\mathrm{CM}$, and the procedure [26-28]. Mehran et al. [27] developed a simple scoring method that integrates eight baseline clinical variables to assess the risk of CIN after percutaneous coronary intervention (PCI). These are hypotension (score 5), the use of an intra-aortic balloon pump (score 5), congestive heart failure (score 5), a serum creatinine level $>1.5 \mathrm{mg} / \mathrm{dl}$ (score 4 ), age $>75$ years (score 4 ), anemia (score 3 ), diabetes mellitus (score 3), and the volume of CM (score $1 / 100 \mathrm{ml}$ ). If the total score is 5 or less, the risk category is low; if the total score is 16 or higher, the risk category is very high.

\section{Patient-Related Risk Factors}

The incidence of CIN is highly dependent on the clinical characteristics of the patients. An overview of the most common patient-related risk factors is given in tables 1-3.

\section{Older Age}

The possible reasons for the high incidence of CIN in elderly patients are age-related changes, such as a dominance of renal vasoconstrictive forces as opposed to renal vasodilatory forces, more difficult vascular access because of tortuosity, calcification of vessels requiring greater amounts of CM, defective prostaglandin synthesis, a decline in prostaglandin $\mathrm{E}_{2}$, and the presence of renovascular diseases $[2,13,29]$. Furthermore, hypovolemia is very common in elderly patients who undergo diagnostic procedures. In a prospective study, in which elderly patients ( $\geq 70$ years) were subjected to cardiac catheterization, $11 \%$ developed CIN [9]. In another study [30], the CIN incidence was $17 \%$ in elderly patients ( $>60$ years) as compared with $4 \%$ in younger patients. Marenzi et al. [16] showed that in 208 patients with acute myocardial infarction, who underwent coronary intervention, an age of 75 years or more was an independent risk factor for CIN $(\mathrm{OR}=5.28, \mathrm{p}=0.0009)$.

\section{Gender}

Ovarian hormones can affect renin-angiotensin system and renal blood flow [31]. In a retrospective study of 8,628 patients who underwent PCI [32], female sex was an independent predictor of CIN (OR $=1.4, \mathrm{p}<0.0001)$. One-year outcome analyses by gender showed a higher mortality among females than among males in a cohort of CIN patients (14 vs. $10 \%, \mathrm{p}=0.05$ ) [32]. The findings of this study contradict those of a previous randomized controlled trial of ionic versus nonionic CM, in which multivariate analysis identified male gender as an independent risk factor for CIN [33]. Whether female gender is truly an independent predictor of CIN will require further confirmatory studies.

\section{Preexisting Renal Disease}

A major risk factor for CIN is a GFR $<60 \mathrm{ml} / \mathrm{min} /$ $1.73 \mathrm{~m}^{2}[1,26,27]$. Cystatin $\mathrm{C}$ is a good GFR marker in cardiologic patients with earlier detection of mild renal dysfunction and allowing a better identification of patients with increased overall risk and those with chance of CM damage $[7,8]$. Chronic kidney disease is associated with a decreased vasodilatory response which is impor- 
tant in developing CIN, and in patients with renal insufficiency, the clearance of CM is slower than in normal subjects. In a study of 7,586 patients who underwent coronary intervention [10], CIN developed in $22.4 \%$ of those who had serum creatinine levels of $2.0-2.9 \mathrm{mg} / \mathrm{dl}$ and in $30.6 \%$ of those with serum creatinine levels of $3.0 \mathrm{mg} / \mathrm{dl}$ or higher as compared with $2.4 \%$ of the patients with serum creatinine levels $<1.1 \mathrm{mg} / \mathrm{dl}$. Moore et al. [34] and Barrett et al. [35] reported that the incidence of CIN increased from 4 to $20 \%$, as the baseline serum creatinine level increased from 1.2 to $2.9 \mathrm{mg} / \mathrm{dl}$. In another study [36], the incidence of CIN increased from 8 to $92 \%$, as the serum creatinine concentration increased from 1.5 to $6.8 \mathrm{mg} / \mathrm{dl}$. Furthermore, the probability of CIN requiring dialysis increased from 0.04 to $48 \%$, as the baseline GFR decreased from 50 to $10 \mathrm{ml} / \mathrm{min}$ [36].

\section{Diabetes Mellitus}

Patients with diabetes constitute an important group at high risk of developing CIN. Nitric-oxide-dependent renal vasodilation is characteristically altered, and the renal outer medullary $\mathrm{pO}_{2}$ is significantly reduced in diabetes [14]. Chronic kidney disease and diabetes mellitus are associated with endothelial dysfunction and decreased vasodilatory responses. Diabetic nephropathy has been identified as a powerful and independent risk factor for CIN [1-3]. Patients with diabetic nephropathy and a mean serum creatinine level of $6.8 \mathrm{mg} / \mathrm{dl}$ had a $92 \%$ incidence of CIN after coronary angiography [37]. Patients with diabetes who have advanced chronic renal failure for causes other than diabetic nephropathy are at a significantly higher risk of developing CIN-like diabetic nephropathy. On the other hand, studies have shown that when preex-
Table 1. Patient-related confirmed risk factors for the development of CIN
Risk Factors for Contrast-Induced Nephropathy

\begin{tabular}{|c|c|c|}
\hline Risk factor & OR $(95 \% \mathrm{CI})$ & $\mathrm{p}$ \\
\hline \multicolumn{3}{|l|}{ Preexisting renal failure } \\
\hline Preprocedural creatinine $2.0-2.9 \mathrm{mg} / \mathrm{dl}[10]^{\mathrm{a}}$ & $7.37(4.78-11.39)$ & $<0.0001$ \\
\hline Preprocedural creatinine $\geq 3 \mathrm{mg} / \mathrm{dl}[10]^{\mathrm{a}}$ & $12.82(8.01-20.54)$ & $<0.0001$ \\
\hline \multicolumn{3}{|l|}{ Diabetes mellitus } \\
\hline Preprocedural creatinine $\leq 1.1 \mathrm{mg} / \mathrm{dl}[10]^{\mathrm{a}}$ & $1.86(1.20-2.89)$ & 0.005 \\
\hline Preprocedural creatinine $1.2-1.9 \mathrm{mg} / \mathrm{dl}[10]^{\mathrm{a}}$ & $2.42(1.54-3.79)$ & $<0.001$ \\
\hline Age $>75$ years $[16]^{\mathrm{b}}$ & $5.28(1.98-14.05)$ & 0.0009 \\
\hline Class III-IV congestive heart failure [28 $]^{\mathrm{c}}$ & $2.20(1.60-2.90)$ & $<0.0001$ \\
\hline Left ventricle ejection fraction $<40 \%[15]^{\mathrm{d}}$ & $1.57(1.14-2.16)$ & 0.005 \\
\hline Periprocedural hypotension $[15]^{\mathrm{d}}$ & $2.50(1.70-3.69)$ & $<0.00001$ \\
\hline Hypertension $[28]^{\mathrm{c}}$ & $2.00(1.40-2.80)$ & 0.0001 \\
\hline Baseline hematocrit $[15]^{\mathrm{d}}$ & $0.95(0.93-0.97)$ & $<0.0001$ \\
\hline Acute myocardial infarction $\leq 24 \mathrm{~h}[10]^{\mathrm{a}}$ & $1.85(1.31-2.63)$ & 0.0006 \\
\hline Peripheral vascular disease $[28]^{\mathrm{c}}$ & $1.90(1.40-2.70)$ & $<0.0001$ \\
\hline Use of ACE inhibitors [49] $]^{\mathrm{e}}$ & $3.37(1.14-9.94)$ & 0.028 \\
\hline
\end{tabular}

Confounding variables that were used in the multivariable logistic regression models were:

a Total volume of CM, age, sex, body mass index, history of congestive heart failure, diabetes, hypertension, metastatic cancer, preprocedure shock, tumor, peptic ulcer disease, peripheral vascular disease, and myocardial infarction within $24 \mathrm{~h}$ before the procedure.

${ }^{\mathrm{b}}$ Age $\geq 75$ years, anterior acute myocardial infarction, time to reperfusion $\geq 6 \mathrm{~h}$, contrast agent volume $\geq 300 \mathrm{ml}$, and use of an intra-aortic balloon pump.

${ }^{\mathrm{c}}$ Creatinine clearance $<60 \mathrm{ml} / \mathrm{min}$, intra-aortic balloon pump use, urgence/emergency procedure, diabetes mellitus, congestive heart failure, hypertension, peripheral vascular disease, and contrast volume $>260 \mathrm{ml}$.

${ }^{\mathrm{d}}$ Estimated GFR, age, female gender, diabetes, previous myocardial infarction, previous coronary artery bypass grafting, African-American race, previous coronary intervention, hypertension, myocardial infarction, stent used, left ventricular ejection fraction $<40 \%$, hyperlipidemia, peripheral arterial disease, history of stroke, body surface area, multivessel percutaneous coronary intervention, congestive heart failure, pulmonary edema on presentation, periprocedural hypotension, intra-aortic balloon pumping, baseline hematocrit, ioxaglate, and contrast/body surface area ratio.

${ }^{e}$ Multivessel involvement, hypoalbuminemia, diabetes mellitus, GFR $\leq 40 \mathrm{ml} / \mathrm{min}$, congestive heart failure, and chronic use of ACE inhibitors. 
isting renal disease is present, patients with and without diabetes are similarly at risk of CIN which correlates with the degree of renal disease $[36,38]$. Some authors have suggested that diabetes mellitus in the absence of nephropathy, particularly in insulin-dependent patients with diabetes, is associated with an increased risk of CIN. In a study performed by Lautin et al. [39], it was found

Table 2. Patient-related possible risk factors for the development of CIN

Hypoalbuminemia [9]

Structural kidney disease or damage [1]

Female gender [32]

Hypercholesterolemia [57]

Cirrhosis of the liver [2]

Nephrotic syndrome [1]

Diuretic usage [12]

Sepsis [2]

Multiple myeloma [53]

Hypertriglyceridemia [71]

Use of nephrotoxic drugs $[50,51]$

Multivessel coronary involvement [27]

Renal artery stenosis [15]

Hyperuricemia [61]

Proteinuria [1]

Renal transplant [67]

Pulmonary edema [15]

Urine albumin-creatinine ratio $>30[1]$

Serum sodium $<135 \mathrm{mEq} / 1$ [9]

Impaired fasting glucose [71]

Metabolic syndrome [71]

Low effective circulatory volume [10] that the incidence of CIN was rather low (2\%) in patients with neither diabetes nor azotemia, significantly higher (16\%) in individuals with diabetes but preserved renal function, and much higher (38\%) in patients who had both diabetes and azotemia. In a study done by Rihal et al. [10], the incidence of CIN was found to be $2 \%$ in patients without diabetes and $3.7 \%$ in patients with diabetes with a baseline creatinine concentration of $1.1 \mathrm{mg} / \mathrm{dl}$ or less $(\mathrm{OR}=1.86, \mathrm{p}=0.005)$. When the renal function is mildly impaired (serum creatinine level $1.2-1.9 \mathrm{mg} / \mathrm{dl}$ ), the risk of CIN in patients with diabetes mellitus increases to $4.5 \%$ $(\mathrm{OR}=2.42, \mathrm{p}<0.001)$ [10]. Other research has failed to detect this connection. For example, Parfrey et al. [40], in an earlier study of patients with diabetes, showed that none of the 85 patients with diabetes and a normal renal function developed clinically significant CIN. However, given that, those with diabetes alone were found to be at a slightly higher risk of developing CIN than the general population [2].

\section{Congestive Heart Failure and Reduced Left \\ Ventricular Ejection Fraction}

Studies have shown that a reduced left ventricular ejection fraction ( $\leq 49 \%)$ and advanced congestive heart failure (New York Heart Association class III or IV) are independent risk factors for CIN [41, 42]. Dangas et al. [15] showed that a left ventricular ejection fraction $<40 \%$ is an independent predictor of CIN. We have previously reported [43] that if the left ventricular ejection fraction is $>30 \%$, this condition does not show any significant effect on the development of CIN. Advanced heart failure and

Table 3. Prevention strategies for CIN in high-risk patients

\begin{tabular}{|c|c|c|}
\hline Clinical evidence advocating the use of & Do not give & $\begin{array}{l}\text { Therapies with conflicting } \\
\text { or limited evidence }\end{array}$ \\
\hline Extracellular volume expansion & $\begin{array}{l}\text { NSAIDs, COX-2 inhibitors, } \\
\text { aminoglycoside, cisplatin, etc. }\end{array}$ & acetylcysteine \\
\hline Isotonic saline (sodium chloride or sodium bicarbonate) & loop diuretics & theophylline \\
\hline Low- or isoosmolar CM & mannitol & atrial natriuretic peptide \\
\hline Minimizing the dose of CM & multiple CM within $72 \mathrm{~h}$ & prostaglandin $\mathrm{E}_{1}$ \\
\hline Alternative imaging techniques & large doses of CM & calcium channel blockers \\
\hline Creatinine measurement before and $48 \mathrm{~h}$ after the procedure & high-osmolar CM & captopril \\
\hline CM delayed until the hemodynamic status is corrected & $\begin{array}{l}\text { metformin, especially in renal failure } \\
\text { patients }\end{array}$ & $\begin{array}{l}\text { fenoldopam } \\
\text { endothelin antagonists } \\
\text { ascorbic acid } \\
\text { hemofiltration }\end{array}$ \\
\hline
\end{tabular}


reduced left ventricular ejection fraction are characterized by effective volume depletion caused by low cardiac output and increased neurohumoral vasoconstrictive stimuli and impaired nitric-oxide-dependent renal vasodilation that might compromise the medullary oxygenation $[3,12,14]$. In the study done by Rihal et al. [10], it was shown that congestive heart failure is an independent risk for CIN (OR $=1.53, \mathrm{p}=0.007$ ). In a cohort study, Bartholomew et al. [28] found that congestive heart failure is a risk for CIN in patients who underwent PCI $(\mathrm{OR}=2.2, \mathrm{p}<0.0001)$.

\section{Hypertension}

An explanation for hypertension as a risk factor for CIN is that alterations in the intrarenal expression of vasoactive mediators, such as the renin-angiotensin system or nitric oxide, may be contributing factors. An impaired nitric-oxide-dependent renal vasodilation is prevalent in individuals who are hypertensive. Finally, a reduced number of nephrons could predispose hypertensive patients to CIN. Hypertension has been categorized as a risk factor for CIN in some research. In a study of 8,628 patients who underwent PCI [32], hypertension was found to be an independent predictor of CIN (OR $=1.2, \mathrm{p}=0.0035)$. In a cohort study, Bartholomew et al. [28] found that hypertension is a risk for CIN in patients who underwent PCI $(\mathrm{OR}=2.0, \mathrm{p}=0.0001)$.

\section{Angiotensin-Converting Enzyme (ACE) Inhibitors}

In some studies [44], ACE inhibitors have been identified as risk factors for CIN because of their potential to reduce the renal function. Some studies have shown that the nephrotoxicity of CM may be reduced because of decreased renal vasoconstriction by inhibition of angiotensin II. Caldicott et al. [45] showed that renal vasoconstriction occurs after CM administration and that the reninangiotensin system is responsible for this vasoconstriction. In another study performed in animals after CM administration [46], there was no significant change in angiotensin II and renin levels. It was found that the suppression of prostacyclin contributed to the renal function changes rather than the activation of the renin-angiotensin system. In a randomized controlled study with 71 patients having diabetes who underwent coronary angiography and were randomized to captopril treatment or the control group [47], $25 \mathrm{mg}$ captopril was given three times daily. There was a significant decrease in CIN in the patients who received captopril as compared with the control group ( 6 vs. $29 \%$, respectively; $p<0.02$ ). We have previously performed a randomized controlled study in
80 patients with a serum creatinine level $<2 \mathrm{mg} / \mathrm{dl}$ who underwent coronary angiography [48]. Captopril was administered to 48 patients before coronary angiography. Five patients $(10.4 \%)$ in the captopril group developed CIN as compared with only 1 patient (3.1\%) in the control group $(p=0.02)$. In a recent study done in 230 patients with renal insufficiency and an age $\geq 65$ years [49], we found that chronic ACE inhibitor administration was a risk factor for developing CIN. CIN occurred in $17 \mathrm{pa}$ tients (15.6\%) of the ACE inhibitor group and in 7 patients $(5.8 \%)$ of the control group $(p=0.015)$. The serum creatinine level increased from $1.34 \pm 0.20$ to $1.53 \pm 0.27 \mathrm{mg} /$ $\mathrm{dl}$ in the ACE inhibitor group and from $1.33 \pm 0.18$ to $1.45 \pm 0.19 \mathrm{mg} / \mathrm{dl}$ in the control group $(\mathrm{p}<0.001)$. Chronic ACE inhibitor administration was a risk indicator of CIN (OR = 3.37, $\mathrm{p}=0.028)$. Checking the use of ACE inhibitors before coronary angiography seems to be useful in the risk assessment for CIN. It is reasonable to suggest that there is a need to hold ACE inhibitor use before coronary angiography.

\section{Nephrotoxic Drugs}

Nephrotoxic drugs and those that inhibit the vasodilatory effects of prostaglandins have been reported to render the kidney more vulnerable to CM [50]. Sulfonamides, aminoglycosides, and their combination with furosemide are particularly potent. Ciclosporin A may intensify medullary hypoxia, and cisplatin can attach to sulfhydryl groups. Mannitol can increase the metabolic work load in the kidney, and amphotericin B can cause the effect of a combination of mannitol and ciclosporin A. However, the individual roles of these medications as independent risk factors of CIN have not been determined in large clinical trials [2]. Nonetheless, it seems quite likely that nonselective NSAIDs and selective COX-2 inhibitors decrease the generation of vasodilatory prostaglandins in the kidney and potentiate the vasoconstrictive effects of CM [51].

\section{Multiple Myeloma}

Multiple myelomas have been suggested as potential risk factors for CIN, on the basis of initial reports. The pathomechanism of this process has been explained by the precipitation of CM molecules together with TammHorsfall proteins and other abnormal proteins, tubular epithelial cells damaged and desquamated as a result of ischemia, direct contrast toxicity, or disturbed function of integrins. In studies conducted in animals, intratubular light chains, particularly in the setting of intravascular volume depletion, have been found to augment the nephrotoxic potential of CM $[52,53]$. Studies with a broader 
scope have since shown that the observed risk is linked to coexisting risk factors, such as preexisting renal insufficiency, low circulating volume, proteinuria, amyloidosis, hyperuricemia, and hypercalcemia, rather than to the myeloma itself [2]. Retrospective studies showed an incidence of CIN of only $0.6-1.25 \%$ in patients with myelomas, if dehydration is avoided [54].

\section{Metformin}

The oral antidiabetic agent metformin is not itself nephrotoxic, but it is known that patients who are receiving metformin may develop lactic acidosis as a result of CIN. A decline in renal function after CM exposure could adversely affect the clearance of metformin. This complication was almost always observed in diabetic patients with decreased renal function before injection of CM. A meta-analysis by the Cochrane Library with pooled data from 176 comparative trials and cohort studies [55] revealed no cases of fatal or nonfatal lactic acidosis in 35,619 patient years of metformin use or in 30,002 patients years in the nonmetformin group. It seems safer and reasonable to instruct patients especially at high risk of developing CIN not to take this drug for $48 \mathrm{~h}$ or so after CM and to resume taking the drug only, if there are no signs of nephrotoxicity $[6,38,56]$.

\section{Hypercholesterolemia}

In the literature, there are only two experimental studies on the relationship between hypercholesterolemia and CIN. According to these studies, hypercholesterolemia aggravates CIN through the reduced production of nitric oxide. Altered nitric-oxide-dependent renal vasodilation, which is important in the pathogenesis of CIN, is prevalent in hypercholesterolemia $[57,58]$.

\section{Hyperuricemia}

It has been suggested that tubular obstruction by uric acid plays a role in the pathogenesis of CIN. CM have a uricosuric effect which appears to be caused by enhanced renal tubular secretion of uric acid [59]. Furthermore, hyperuricemia is accompanied by an enhanced synthesis of reactive oxygen species, an activated renin-angiotensinaldosterone system, increased endothelin-1 levels, and an inhibited nitric oxide system which play a role in the pathogenesis of CIN [60]. In a recent prospective cohort study [61], we evaluated 266 patients who underwent elective coronary angiography, and we found that patients with hyperuricemia are at risk of developing CIN (OR = $4.71, \mathrm{p}=0.019$ ). CIN occurred in $15.1 \%$ of the hyperuricemic group and in $2.9 \%$ of the normouricemic group $(p<0.001)$. Longer hospital stays $(p<0.001)$ and CIN requiring renal replacement therapy $(p=0.017)$ were significantly more prevalent in the hyperuricemic group. Serum uric acid levels $\geq 7 \mathrm{mg} / \mathrm{dl}$ in males and $\geq 5.9 \mathrm{mg} / \mathrm{dl}$ in females were found to be the best cutoff values for the prediction of CIN [61].

\section{Multivessel Coronary Involvement, Peripheral \\ Vascular Disease, and Renal Artery Stenosis}

Factors related to accelerated or diffuse atherosclerosis are linked to the development of CIN [15]. The treatment of multivessel disease, challenging chronic total occlusions and extensively diseased coronary segments, may require high doses of $\mathrm{CM}$ for providing an optimal image quality, thus enhancing the potential toxic effects on the renal function. If a patient has multivessel coronary involvement, the other vessels in the body, such as the renal artery, can be involved. If the renal artery is involved, the renal blood supply may decrease, and the kidneys may be more susceptible to CIN. In a study of 177 patients who underwent cardiac catheterization [62], they were also evaluated for renal artery stenosis. Coronary artery disease was detected in 110 patients (62\%), and significant renal artery stenosis was detected in 19 patients (11\%). Using multivariate analysis, it was found that the extent of coronary artery disease was an independent predictor of renal artery stenosis [62]. We found only one study that evaluated multivessel coronary involvement as a risk predictor of CIN in addition to the well-known CIN risk factors. A total of 5,571 patients who underwent PCI were evaluated for CIN risk factors, and it was found that multivessel coronary involvement was only a univariate predictor of CIN ( $p=0.003)$ [27]. In a cohort study by Bartholomew et al. [28] and in another study by Rihal et al. [10], it was found that peripheral vascular disease is a risk for CIN in patients who underwent PCI $(\mathrm{OR}=1.9, \mathrm{p}<$ 0.0001 , and $\mathrm{OR}=1.71, \mathrm{p}=0.001$, respectively).

\section{Hypovolemia}

Decreased effective circulating volume and reduced renal perfusion potentiate renal vasoconstriction after administration of intravascular CM [52, 63, 64]. Hypovolemia leads to active sodium reabsorption, which is an oxygen-demanding process, and increases neurohumoral vasoconstrictive stimuli that might compromise medullary oxygenation [14]. The toxic effects of CM on the renal tubular lumen may be exacerbated in hypovolemia [65]. Upon injection of CM, fluid shifts from tissues into the vascular system, and this leads to a decreased circulating volume. Volume expansion reduces the activity of the re- 
nin-angiotensin system, minimizes increases in blood viscosity and osmolality, and increases medullary perfusion $[11,18]$. At present, the most convincing preventive procedure of CIN is adequate hydration with isotonic saline or sodium bicarbonate $[6,13]$, and intravenous hydration seems to have better results than does oral hydration. Before angiography, the volume status of high-risk patients can be assessed through inferior vena cava index, mean atrial pressure, or pulmonary-capillary wedge pressure [66].

\section{Renal Transplantation}

Patients with renal transplantation may be at a higher risk of developing CIN due to the concomitant use of ciclosporin and the higher prevalence of diabetes and renal insufficiency. Ahuja et al. [67] studied 33 patients with a functioning renal allograft who underwent different $\mathrm{CM}$ studies, and the incidence of CIN was $21.2 \%$.

\section{Acute Myocardial Infarction}

A study performed by Rihal et al. [10] showed that acute myocardial infarction within $24 \mathrm{~h}$ before administration of the $\mathrm{CM}$ is a risk factor for $\mathrm{CIN}(\mathrm{OR}=1.85, \mathrm{p}=$ 0.0006). This study demonstrated that CIN is a frequent complication in acute myocardial infarction, even in patients with a normal baseline renal function. Marenzi et al. [16] showed that in 208 acute myocardial infarction patients who underwent primary PCI, the incidence of anterior acute myocardial infarction was significantly higher in patients who developed CIN ( $\mathrm{p}=0.0015)$. However, in multivariate analysis, anterior acute myocardial infarction $(\mathrm{OR}=2.17, \mathrm{p}=0.09)$ was not a risk predictor of CIN [16]. In 2,082 PCIs for acute myocardial infarction, Sadeghi et al. [68] reported a more than sevenfold (3.2 vs. $23.3 \%)$ increase in the 1-year mortality in patients who developed CIN.

\section{Low Hematocrit Level}

Anemia-induced deterioration of renal ischemia may be one plausible explanation for the higher incidence of $\mathrm{CIN}$ in patients with a low hematocrit level. A baseline hematocrit value $<39 \%$ for men and $<36 \%$ for women is a risk for developing CIN [1]. The relationship between low hematocrit levels and CIN has been investigated by Nikolsky et al. [69] in a prospective study of 6,773 patients who underwent PCI. A lower baseline hematocrit was an independent predictor of CIN, and each $3 \%$ decrease in baseline hematocrit resulted in a significant increase in the odds of CIN in patients with and without chronic kidney disease (11 and 23\%, respectively). Dangas et al. [15] showed that the baseline hematocrit level is an independent predictor of CIN in patients with chronic kidney disease $(\mathrm{OR}=0.95, \mathrm{p}<0.00001)$.

\section{Low Serum Albumin Level}

Hypoalbuminemia impairs the endothelial function, enhances the renal vasoconstriction, impairs the synthesis and release of nitric oxide, and decreases the antioxidant enzyme activity [70]. In the literature, we found only one study on the association between serum albumin and CIN. In this study [9], a low serum albumin concentration $(<3.5 \mathrm{~g} / \mathrm{dl})$ was identified as a risk factor for CIN in patients 70 years of age or older who underwent cardiac catheterization.

Hypotension, Sepsis, Cirrhosis, and Pulmonary Edema

A systolic blood pressure $<80 \mathrm{~mm} \mathrm{Hg}$ for at least $1 \mathrm{~h}$ that requires inotropic support with medications is a risk factor for CIN [1]. A study performed by Dangas et al. [15] showed that periprocedural hypotension and pulmonary edema are independent predictors of CIN in patients with chronic kidney disease $(\mathrm{OR}=2.50, \mathrm{p}<0.00001$, and $\mathrm{OR}=2.56, \mathrm{p}=0.001$, respectively). Sepsis, through direct damage by bacterial toxins to renal tubules and impairment of the circulation, has also been reported as a risk factor [2]. Reduction of effective intravascular volume caused by liver cirrhosis has been reported as contributing to prerenal reduction in renal perfusion, thus enhancing the ischemic insult of CM [2].

\section{Metabolic Syndrome, Impaired Fasting Glucose, and Hypertriglyceridemia}

In a recent prospective cohort study of 219 nondiabetic elderly patients with reduced kidney function who underwent elective coronary angiography [71], we reported that metabolic syndrome was a risk indicator of CIN $(\mathrm{OR}=4.26, \mathrm{p}=0.026)$. CIN occurred in $14 \%$ of the patients of the metabolic syndrome group and in $3.6 \%$ of those of the nonmetabolic syndrome group (relative risk $3.93, \mathrm{p}=0.007)$. Impaired fasting glucose $(\mathrm{OR}=4.72, \mathrm{p}=$ $0.007)$, high triglyceride levels $(\mathrm{OR}=4.06, \mathrm{p}=0.022)$, and multivessel involvement $(\mathrm{OR}=3.14, \mathrm{p}=0.038)$ in the metabolic syndrome group were predictors of CIN [71].

\section{Procedure- and Contrast-Agent-Related Risk Factors}

The most common risk factors for developing CIN are (1) a high total dose of CM [72]; (2) a high osmolality of the CM [13]; (3) a high ionic content of the CM [33, 73]; 
(4) a high viscosity of the CM $[11,12,74]$; (5) intra-arterial administration of the CM $[2,75]$; (6) less than 2 days between the contrast-using procedures $[2,6,12] ;(7)$ urgency/emergency procedures [28]; (8) the use of an intraaortic balloon pump [15, 16, 24, 28], and (9) bypass graft intervention and delayed reperfusion $[16,76]$.

\section{Conclusions}

The development of CIN is associated with adverse outcomes, including a prolonged hospitalization, the potential need for renal replacement therapy, and, most im- portantly, an increased mortality. A careful evaluation of each patient who is to receive intravascular $\mathrm{CM}$ for the presence of underlying risk factors for CIN is essential.

\section{Acknowledgments}

This study was supported by a grant from the Turkish Society of Nephrology. We would like to express our deep appreciation to Dr. Alp Ikizler, Division of Nephrology, Vanderbilt University School of Medicine, Nashville, Tenn., USA, for his insight and editorial assistance.

\section{References}

1 McCullough PA, Soman SS: Contrast-induced nephropathy. Crit Care Clin 2005;21:261280.

$\checkmark 2$ Gleeson TG, Bulugahapitiya S: Contrast-induced nephropathy. AJR Am J Roentgenol 2004;183:1673-1689.

-3 Gami AS, Garovic VD: Contrast nephropathy after coronary angiography. Mayo Clin Proc 2004;79:211-219.

4 Lepor NE: Radiocontrast nephropathy: the dye is not cast. Rev Cardiovasc Med 2000;1: 43-54.

5 Itoh Y, Yano T, Sendo T, et al: Clinical and experimental evidence for prevention of acute renal failure induced by radiographic contrast media. J Pharmacol Sci 2005;97:473-488.

-6 Morcos SK, Thomsen HS; European Society of Urogenital Radiology: European Society of Urogenital Radiology guidelines on administering contrast media. Abdom Imaging 2003; 28:187-190.

7 McDougal WS: Early detection of acute renal failure by serum cystatin C. J Urol 2005;174: 1024-1025.

-8 Artunc FH, Fischer IU, Risler T, et al: Improved estimation of GFR by serum cystatin $\mathrm{C}$ in patients undergoing cardiac catheterization. Int J Cardiol 2005;102:173-178.

$\checkmark 9$ Rich MW, Crecelius CA: Incidence, risk factors, and clinical course of acute renal insufficiency after cardiac catheterization in patients 70 years of age or older: a prospective study. Arch Intern Med 1990;150:1237-1242.

10 Rihal CS, Textor SC, Grill DE, et al: Incidence and prognostic importance of acute renal failure after percutaneous coronary intervention. Circulation 2002;105:2259-2264

11 Persson PB, Hansell P, Liss P: Pathophysiology of contrast medium-induced nephropathy. Kidney Int 2005;68:14-22.

12 Goldenberg I, Matetzky S: Nephropathy induced by contrast media: pathogenesis, risk factors and preventive strategies. CMAJ 2005; 172:1461-1471.
3 Detrenis S, Meschi M, Musini S, et al: Lights and shadows on the pathogenesis of contrastinduced nephropathy: state of the art. Nephrol Dial Transplant 2005;20:1542-1550.

14 Heyman SN, Rosenberger C, Rosen S: Regional alterations in renal haemodynamics and oxygenation: a role in contrast medium-induced nephropathy. Nephrol Dial Transplant Suppl 2005;20:6-11.

15 Dangas G, Iakovou I, Nikolsky E, et al: Contrast-induced nephropathy after percutaneous coronary interventions in relation to chronic kidney disease and hemodynamic variables. Am J Cardiol 2005;95:13-19.

16 Marenzi G, Lauri G, Assanelli E, et al: Contrast-induced nephropathy in patients undergoing primary angioplasty for acute myocardial infarction. J Am Coll Cardiol 2004;44: 1780-1785.

17 Levy EM, Viscoli CM, Horwitz RI: The effect of acute renal failure on mortality: a cohort analysis. JAMA1996;275:1489-1494.

18 Maeder M, Klein M, Fehr T, et al: Contrast nephropathy: review focusing on prevention. J Am Coll Cardiol 2004;44:1763-1771.

19 Ide JM, Lancelot E, Pines E, et al: Prophylaxis of iodinated contrast media-induced nephropathy: a pharmacological point of view. Invest Radiol 2004;39:155-170.

20 Lin J, Bonventre JV: Prevention of radiocontrast nephropathy. Curr Opin Nephrol Hypertens 2005; 14:105-110.

21 Asif A, Epstein M: Prevention of radiocontrast-induced nephropathy. Am J Kidney Dis 2004;44:12-24.

22 Erley CM, Bader BD, Berger ED, et al: Gadolinium-based contrast media compared with iodinated media for digital subtraction angiography in azotaemic patients. Nephrol Dial Transplant 2004;19:2526-2531.
23 Ergun I, Keven K, Uruc I, et al: The safety of gadolinium in patients with stage 3 and 4 renal failure. Nephrol Dial Transplant 2006;21:697700 .

24 Jakobsen JA, Oyen R, Thomsen HS, et al; Members of Contrast Media Safety Committee of European Society of Urogenital Radiology (ESUR): Safety of ultrasound contrast agents. Eur Radiol 2005;15:941-945.

25 Gomes VO, Poli de Figueredo CE, et al: N-acetylcysteine does not prevent contrast induced nephropathy after cardiac catheterisation with an ionic low osmolality contrast medium: a multicentre clinical trial. Heart 2005;91: 774-778.

26 Toprak O, Cirit M, Bayata S, et al: Review of the radiocontrast nephropathy risk profiles and risk stratification. Anadolu Kardiyol Derg 2004;4:331-335.

27 Mehran R, Aymong ED, Nikolsky E, et al: A simple risk score for prediction of contrastinduced nephropathy after percutaneous coronary intervention: development and initial validation. J Am Coll Cardiol 2004;44:13931399.

28 Bartholomew BA, Harjai KJ, Dukkipati S, et al: Impact of nephropathy after percutaneous coronary intervention and a method for risk stratification. Am J Cardiol 2004;93:15151519.

29 Prasad PV, Epstein FH: Changes in medullary $\mathrm{pO}_{2}$ during water diuresis as evaluated by blood oxygen level-dependent magnetic resonance imaging. Kidney Int 1999;55:294-298.

- 30 Kohli HS, Bhaskaran MC, Muthukumar T, et al: Treatment-related acute renal failure in the elderly: a hospital-based prospective study. Nephrol Dial Transplant 2000;15:212-217.

31 Kisley LR, Sakai RR, Flanagan-Cato LM, et al: Estrogen increases angiotensin II-induced cFos expression in the vasopressinergic neurons of the paraventricular nucleus in the female rat. Neuroendocrinology 2000;72: 306-317. 
32 Iakovou I, Dangas G, Mehran R, et al: Impact of gender on the incidence and outcome of contrast-induced nephropathy after percutaneous coronary intervention. J Invasive Cardiol 2003;15:18-22.

>33 Rudnick MR, Goldfarb S, Wexler L, et al: Nephrotoxicity of ionic and nonionic contrast media in 1,196 patients: a randomized trial. The Iohexol Cooperative Study. Kidney Int 1995;47:254-261.

>34 Moore RD, Steinberg EP, Powe NR, et al. Nephrotoxicity of high-osmolarity vs low-osmolarity contrast media: randomized clinical trial. Radiology. 1992;182:649-655.

-35 Barrett BJ, Parfrey PS, Vavasour HM, et al: Contrast nephropathy in patients with impaired renal function: high versus low osmolar media. Kidney Int 1992;41:1274-1279.

-36 McCullough PA, Wolyn R, Rocher LL, et al: Acute renal failure after coronary intervention: incidence, risk factors, and relationships to mortality. Am J Med 1997;103:368-375.

>37 Weinrauch LA, Healy RW, Leland OS Jr, et al: Coronary angiography and acute renal failure in diabetic azotemic nephropathy. Ann Intern Med 1977;86:56-59.

>38 Asif A, Preston RA, Roth D: Radiocontrastinduced nephropathy. Am J Ther 2003;10: 137-147.

-39 Lautin EM, Freeman NJ, Schoenfeld AH, et al: Radiocontrast-associated renal dysfunction: incidence and risk factors. AJR Am J Roentgenol 1991;157:49-58.

-40 Parfrey PS, Griffiths SM, Barrett BJ, et al: Contrast material-induced renal failure in patients with diabetes mellitus, renal insufficiency, or both: a prospective controlled study. N Engl J Med 1989;320:143-149.

41 Gruberg L, Mintz GS, Mehran R, et al: The prognostic implications of further renal function deterioration within $48 \mathrm{~h}$ of interventional coronary procedures in patients with preexistent chronic renal insufficiency. J Am Coll Cardiol 2000;36:1542-1548.

42 Schillinger M, Haumer M, Mlekusch W, et al: Predicting renal failure after balloon angioplasty in high-risk patients. J Endovasc Ther 2001;8:609-614.

43 Toprak O, Cirit M, Bayata S, et al: Is there any relationship between left ventricular ejection fraction and contrast induced nephropathy? Turk Klin J Med Sci 2003;23:104-107.

44 Louis BM, Hoch BS, Hernandez C, et al: Protection from the nephrotoxicity of contrast dye. Ren Fail 1996;18:639-646.

45 Caldicott WJ, Hollenberg NK, Abrams HL: Characteristics of response of renal vascular bed to contrast media: evidence for vasoconstriction induced by renin-angiotensin system. Invest Radiol 1970;5:539-547.

-46 Workman RJ, Shaff MI, Jackson RV, et al: Relationship of renal hemodynamic and functional changes following intravascular contrast to the renin-angiotensin system and renal prostacyclin in the dog. Invest Radiol 1983;18:160-166.
47 Gupta RK, Kapoor A, Tewari S, et al: Captopril for preventing of contrast-induced nephropathy in diabetic patients: a randomized study. Indian Heart J 1999;51:521-526.

48 Toprak O, Cirit M, Bayata S, et al: The effect of pre-procedural captopril on contrast-induced nephropathy in patients who underwent coronary angiography. Anadolu Kardiyol Derg 2003;3:98-103.

49 Cirit M, Toprak O, Yesil M, et al: Angiotensinconverting enzyme inhibitors as a risk factor for contrast-induced nephropathy. Nephron Clin Pract 2006;104:20-27.

50 Jabs K, Zeidel ML, Silvia P: Prostaglandin E inhibits $\mathrm{Na}^{+}-\mathrm{K}^{+}$-ATPase activity in the inner medullary collecting duct. Am J Physiol 1989; 257(3 Pt 2):F424-F430.

51 Kolonko A, Kokot F, Wiecek A: Contrast-associated nephropathy - old clinical problem and new therapeutic perspectives. Nephrol Dial Transplant 1998;13:803-806.

52 Weisbord SD, Palevsky PM: Radiocontrastinduced acute renal failure. J Intensive Care Med 2005;20:63-75.

53 Holland MD, Galla JH, Sanders PW, et al: Effect of urinary $\mathrm{pH}$ and diatrizoate on Bence Jones protein nephrotoxicity in the rat. Kidney Int 1985;27:46-50.

54 McCarthy CS, Becker JA: Multiple myeloma and contrast media. Radiology 1992;183:519521.

55 Salpeter S, Greyber E, Pasternak G, et al: Risk of fatal and nonfatal lactic acidosis with metformin use in type 2 diabetes mellitus. Cochrane Database Syst Rev 2003;2:CD002967.

56 Nawaz S, Cleveland T, Gaines PA, et al: Clinical risk associated with contrast angiography in metformin treated patients: a clinical review. Clin Radiol 1998;53:342-344.

57 Andrade L, Campos SB, Seguro AC: Hypercholesterolemia aggravates radiocontrast nephrotoxicity: protective role of arginine. Kidney Int 1998;53:1736-1742.

58 Yang DW, Jia RH, Yang DP, et al: Dietary hypercholesterolemia aggravates contrast media-induced nephropathy. Chin Med J 2004; 117:542-546.

59 Postlethwaite AE, Kelley WN: Uricosuric effect of radiocontrast agents: a study in man of four commonly used preparations. Ann Intern Med 1971;74:845-852.

60 Perlstein TS, Gumieniak O, Hopkins PN, et al: Uric acid and the state of the intrarenal reninangiotensin system in humans. Kidney Int 2004;66:1465-1470.

61 Toprak O, Cirit M, Esi E, et al: Hyperuricemia as a risk factor for contrast-induced nephropathy in patients with chronic kidney disease. Catheter Cardiovasc Interv 2006;67:227-235.
62 Weber-Mzell D, Kotanko P, Schumacher M, et al: Coronary anatomy predicts presence or absence of renal artery stenosis: a prospective study in patients undergoing cardiac catheterization for suspected coronary artery disease. Eur Heart J 2002;23:1684-1691.

63 Dudzinski PJ, Petrone AF, Persoff M, et al: Acute renal failure following high dose excretory urography in dehydrated patients. J Urol 1971;106:619-621.

64 Nygren A, Ulfendahl HR: Effects of high- and low-osmolar contrast media on renal plasma flow and glomerular filtration rate in euvolaemic and dehydrated rats. Acta Radiol 1989;30: 383-389.

65 Katzberg RW: Contrast medium-induced nephrotoxicity: which pathway? Radiology 2005;235:752-725.

66 Toprak O, Cirit M: Investigating the volume status before contrast nephropathy studies. Nephrol Dial Transplant 2005;20:464.

67 Ahuja TS, Niaz N, Agraharkar M: Contrastinduced nephrotoxicity in renal allograft recipients. Clin Nephrol 2000;54:11-14.

68 Sadeghi HM, Stone GW, Grines CL, et al: Impact of renal insufficiency in patients undergoing primary angioplasty for acute myocardial infarction. Circulation 2003; 108: 2769-2775.

-69 Nikolsky E, Mehran R, Lasic Z, et al: Low hematocrit predicts contrast-induced nephropathy after percutaneous coronary interventions. Kidney Int 2005;67:706-713.

70 Vuong TD, Braam B, Willekes-Koolschijn N, et al: Hypoalbuminaemia enhances the renal vasoconstrictor effect of lysophosphatidylcholine. Nephrol Dial Transplant 2003;18: 1485-1492.

71 Toprak O, Cirit M, Yesil M, et al: Metabolic syndrome as a risk factor for contrast-induced nephropathy in non-diabetic elderly patients with renal impairment. Kidney Blood Press Res 2006;29:2-9.

72 Cigarroa RG, Lange RA, Williams RH, et al: Dosing of contrast material to prevent contrast nephropathy in patients with renal disease. Am J Med 1989;86:649-652.

73 Soejima K, Uozumi J, Kanou T, et al: Nonionic contrast media are less nephrotoxic than ionic contrast media to rat renal cortical slices. Toxicol Lett 2003;143:17-25.

74 Baker CS, Wragg A, Kuna S, et al: A rapid protocol for the prevention of contrast-induced renal dysfunction: The RAPPID Study. J Am Coll Cardiol 2003;41:2114-2118.

75 Byrd L, Sherman R: Radiocontrast-induced acute renal failure: a clinical and pathophysiologic review. Medicine (Baltimore) 1979;58: 270-279.

76 Gruberg L, Mehran R, Dangas G, et al: Acute renal failure requiring dialysis after percutaneous coronary interventions. Catheter Cardiovasc Interv 2001;52:409-416. 